\title{
Recepción de la narrativa social europea en Chile (1880-1920)*
}

\author{
Jaime Galgani**
}

\section{Resumen}

Durante la década 1880-1890, se dieron fenómenos importantes que impulsaron el cambio de paradigma en el mercado del consumo literario y en la producción narrativa. Uno de ellos fue la llegada, lectura y recepción -en revistas y cenáculos- de la obra de escritores europeos vinculados al realismo y al naturalismo principalmente. Dichas escuelas, creadoras de una estética narrativa propia, son apropiadas en Chile de tal manera que generaron un fenómeno único de producción literaria que tiene su motivación fundamental en la cuestión social como motor del relato.

Palabras clave: novela social, cuestión social, naturalismo, realismo, recepción, apropiación

\begin{abstract}
Throughout the 1880-1890 decade, a series of important events occurred that promoted a paradigm shift in the market of literary consumption and narrative production. One of those was the arrival, reading and reception -in magazines and inner circles- of the work of European authors linked mainly to realism and naturalism. These schools, creators of a unique aesthetics narrative, are appropriated here in Chile in such a way that they caused a distinctive phenomenon of literary production that finds a fundamental motivation in social aspects as the driven-force of story.
\end{abstract}

Key words: social novel, social aspects, naturalism, realism, reception, appropriation

* Este artículo forma parte de la investigación realizada por el profesor Jaime Galgani en el proyecto que preside: iniciación FONDECyT n ${ }^{\circ} 11090054$, "Literatura chilena y proyecto cultural en revistas de inicios del siglo XX (1900-1910)", y está escrito sobre la base de una ponencia presentada en el seminario titulado "Segundas jornadas de historia de las izquierdas en Chile" (24 de mayo de 2010).

** Doctor en literatura, académico Departamento de Humanidades Universidad Católica Silva Henríquez, jgalganim@ucsh.cl 


\section{Introducción}

Novela social y cuestión social son conceptos que se relacionan estrechamente en el proyecto literario de la narrativa chilena a fines del siglo XIX y en las primeras décadas del siglo XX. Muchos narradores, hijos de un nuevo tiempo y testigos de una nueva concepción de la literatura, más autónomos y más consagrados a la creación literaria que sus antecesores, quienes habían visto la literatura como una labor subordinada a su oficio principal, contribuyen a armar un mapa de la situación social de su tiempo a través del registro escrito. Se entiende que, para ellos, la "cuestión social" era una urgencia que subordinaba la práctica escritural a cualquier otro proyecto estético. Había un mundo que contar, había unos "vicios" que denunciar, había una oscura ley que gobernaba el quehacer de los más débiles y que necesitaban plasmar. Conformada por hombres o por bestias, había una sociedad que reflejar en una literatura que entendía, por entonces, su función como la de ser un espejo de la realidad.

En efecto, la literatura europea que llega a los cenáculos, tertulias, ateneos, salones y revistas literarias a partir de 1880 impacta a los intelectuales, lectores y escritores especialmente con las obras de sus autores realistas y naturalistas, entre los cuales descuellan los tratados monumentales de Flaubert, Balzac, Tolstoi y Zola. La recepción de La Comedia Humana, Madame Bovary, La Guerra y la paz, Germinal, entre otras, terminará por influir notablemente en la producción literaria nacional de los años siguientes. Lo hará de una manera propia, integrando tendencias y escuelas de manera muy particular según lo orienten los intereses, las lecturas y las motivaciones de los escritores, cada cual con un acento especial.

Este artículo, pues, revisa el proceso de la llegada de la novela social a Chile, sus primeras recepciones, su impacto en el campo cultural, la forma en que influye en las temáticas de los nuevos escritores, el mapa de la sociedad chilena que es posible leer a través de la vasta producción narrativa generada por los más reconocidos narradores de entre siglos. Se plantea como hipótesis el hecho de que la recepción de los escritores europeos marcó el horizonte de la producción escritural. Metodológicamente se leen las principales lecturas que 
se han hecho del fenómenos y se consideran los artículos de revistas literarias de la primera mitad del siglo XX.

\section{Dos paradigmas en la historia literaria chilena y la inclusión de la cuestión social}

La enseñanza de la historia de la literatura chilena en nuestras instituciones educativas adolece de un defecto básico que ya algunos estudiosos y críticos han aclarado convenientemente, pero que no se ha instalado aún como un discurso reconocido. Se trata de presentar a nuestros escritores en un continuum que comienza con Andrés Bello y llega hasta Bolaño y Eltit no haciendo más distinciones que aquellas que derivan de cuestiones temáticas, generacionales o epocales, cuestión que sin duda resulta provechosa pero que no insiste suficientemente en que hay dos modos claramente distintos de concebir, hacer, y recepcionar la literatura, dos modos que configuran por sí mismos dos paradigmas, dos proyectos, dos entendimientos de la función de la literatura en la sociedad y que, sucedidos en dos épocas históricas fundamentales de nuestra vida republicana, han cumplido un papel relevante y rector en la materia. Más concretamente, se está distinguiendo aquí al escritor decimonónico (claramente identificado con los procesos constructivos de la nación chilena) del escritor posterior, arribado a fines del siglo XIX e inicios del XX y que configura un "nuevo cuño", quizás prevalente hasta nuestros días. El punto de quiebre entre estas dos modalidades escriturales se da históricamente a partir de la crisis nacional de 1891 y el surgimiento de una elite intelectual que vendría a dar sus primeros frutos ya maduros a partir de 1900, pero que ya era preparada en los cenáculos de las tertulias finiseculares, entre las cuales destacan las habidas por el grupo reunido en torno a Pedro Balmaceda Toro en la década de los ‘80 del primer siglo de nuestra historia republicana.

¿Quién era y cómo concebía la literatura el escritor de antiguo cuño? El escritor del siglo XIX cumplía en general con el perfil de un actor público, comprometido con la definición institucional, económica y política del país; en muchos casos, era un estadista que tenía múltiples funciones como ministro, diplomático; en no pocas situaciones, además, pertenecía a la oligarquía chilena, tenía intereses económicos vinculados a la tierra, la minería o la industria portuaria; siempre respondía a la imagen del hombre letrado. Cuando funge como creador literario lo hace de forma complementaria, ya sea para secundar sus proyectos políticos (Bello, Lastarria, Blest Gana), ya sea para adornar su trabajo con una creación literaria más vinculada al divertimento y al ornamento.

Más allá de las figuras de Lastarria, Andrés Bello, Barros Arana o Alberto Blest Gana, es frecuente encontrar en tareas propiamente literarias a prominentes políticos de la época, como es el caso, por ejemplo, de don Carlos Walker Martínez... (Catalán 91) 
No existía entre estos escritores la concepción de especialización literaria, sino que se daban al cultivo de los más variados géneros:

... junto con asumir las funciones tanto de liderazgo y dirección política como de productor literario, el intelectual del siglo XIX que se genera al interior mismo de las clases dominantes - cultiva indistinta o simultáneamente todos aquellos géneros que pertenecen o lindan con la literatura: consumado "diarista", es también poeta, orador, novelista, crítico, jurista, historiador, filólogo, cronista. (Catalán 91)

El escritor de nuevo cuño, en cambio, responderá a otra matriz: procedente de distintas clases sociales (varios de la mesocracia emergente), desvinculado en términos generales de las funciones políticas o de la regencia económica de la nación, a veces asociado a puestos de la administración pública o a la redacción de algunos periódicos, su ejercicio literario estará vinculado más bien a una creciente profesionalización del oficio, y, sobre todo, a también crecientes grados de autonomía con respecto a los campos dominantes. Esta nueva situación del escritor, que corresponde, en términos generales, al proceso de especialización inaugurado por la modernidad, permitirá generar, como rasgo específico suyo, un tipo de creación literaria que destacará por su posicionamiento crítico frente a diversas instancias que nuclean las bases estructurantes del poder. Representan este modelo nombres de escritores como Baldomero Lillo, Luis Orrego Luco, Augusto D'Halmar, Joaquín Edwards Bello, Manuel Rojas, Gabriela Mistral, Pablo Neruda, etc.

El cambio, naturalmente, es de orden sistémico e involucra no sólo un nuevo modo de ser escritor, sino también nuevas temáticas y, consecuentemente, nuevas influencias. En este sentido, desde la década de 1880-90, se da con fuerza en Chile la recepción literaria de autores que renuevan el mapa de lecturas y dinamizan el consumo literario del siglo. Este proceso, encauzado nuevamente por el grupo de Balmaceda Toro, será, junto a otros elementos (Certamen Varela de 1887, Diario La Época (desde 1885), tertulias literarias, etc.) el motivador de un cambio de mentalidad decisivo para el futuro de las letras chilenas.

Este grupo, la "bohemia dorada" de la época, constituye pese a la procedencia aristocrática de algunos de sus miembros, la primera promoción donde es posible apreciar elementos de ruptura con el pasado literario inmediato. Más interesados en la literatura que en la política, se anuncia en ellos una sensibilidad definitivamente moderna y esteticista hacia las letras. En la mesa de trabajo de Pedro Balmaceda - uno de los amigos más fieles de Darío - destacaban, según el testimonio de Orrego Luco, las últimas novedades europeas, y las obras de Goncourt, Daudet, Mallarmée, Verlaine, Gauthier se confundían con libros de arte y con las reproducciones de los emergentes impresionistas. (Catalán 105-106) 
De la mesa del joven hijo del presidente Balmaceda, en donde se intercambiarían los comentarios que entre los contertulios producían estas nuevas lecturas, se dio el paso siguiente que consistió en la recepción literaria y crítica de los recién llegados escritores europeos en las revistas y periódicos:

La inquietud del grupo pronto se proyectó a La Época y en las páginas del diario las novelas de folletín se entreveran con las narraciones de Maupassant, Daudet, Anatole France, Pérez Galdós y con los ensayos de José Martí, Menéndez Pelayo y Emilio Castelar. En forma sistemática sus columnas empiezan a incluir noticias y artículos bibliográficos acerca de las letras francesas, inglesas e italianas, junto con informar de lo que ocurre en el terreno de las artes en el Viejo Mundo. De igual modo, la publicidad literaria que La Época comienza a insertar en sus ediciones contribuye a renovar el gusto literario de sus lectores. Y las novedades que el diario publicita nos da la medida de la renovación que empieza a gestarse: predominan los autores franceses -Taine, Daudet, Zola, Maupassant, Mallarmée, Goncourt-, los españoles -Pérez Galdós, Palacio Valdés, Menéndez y Pelayo- y también los rusos, que comienzan a darse a conocer -Turgueniev, Dostoyewski, Puskin, Tolstoi-. (Catalán 106)

Este acontecer múltiple de procesos convergentes en la consolidación del campo literario y en la articulación de su autonomía relativa genera una dinámica en donde la inquietud literaria de los miembros del mismo produce movimientos de incorporación de nuevos escritores, los que, después de pasar por la tertulia y el "salón", son recepcionados en el órgano escrito por excelencia, que es la revista literaria (semanario o suplemento, cualquiera sea su forma). La revista literaria se convierte en necesidad lógica de este crecimiento, atendiendo además a la realidad de un público consumidor que, en virtud del proceso de la apertura a la cultura de masas, lenta pero progresivamente va cada vez en aumento.

Nosotros, desde el siglo XXI, no tenemos acceso a los diálogos que hubo en las tertulias sobre las nuevas lecturas. Nuestra forma de llegar a ellos es la revista literaria, la cual recoge y cristaliza, de algún modo, el proceso de recepción y ofrece luces para comprender la configuración propia del campo cultural.

A inicios del siglo XX, las revistas Pluma i Lápiz, Instantáneas, Luz i sombra, Instantáneas de luz i sombra, Selecta contribuirán a la maduración de la revista como órgano escrito fundamental al interior del campo literario, ya sea por las razones expresadas como por la importancia que tendrán para la profesionalización de la crítica literaria.

Ahora bien, atendiendo a la temática que interesa en este artículo, es posible rastrear en estas revistas la recepción de los escritores extranjeros y de las tendencias y escuelas que representaban. Una de ellas, quizás la que absorbió durante un tiempo gran parte de la atención fue la escuela literaria vinculada 
al desarrollo en Europa del realismo y el naturalismo literarios. Tolstoi, Zola y Daudet son los principales representantes de estas narrativas; su importancia se tradujo a tres manifestaciones concretas: publicación de relatos o extractos de sus obras, recepción crítica de la misma, e influencia en la creación literaria de las primeras décadas del siglo XX.

\section{Primera recepción de la novela social europea}

Cuando en Chile se vivía aún de La Corina de Madame Stael, de El Moro Expósito del Duque de Rivas, de los versos de Espronceda, de las novelas de Dumas, de los poemas de Bécquer, y de la incipiente poesía y novela chilenas, mucho impacto debió de causar el conocimiento de los novelistas rusos y franceses que comenzaban a ser leídos. Así lo destaca Domingo Melfi:

Al terminar los capítulos de Zola, de Gorki o Dostoyewski, los lectores que levantaban la cabeza del libro descubrían la mentira del mundo que les rodeaba. En todos los rincones encontraban la confirmación de aquellos humillados y ofendidos que pululaban como desechos en el mundo novelesco de Europa y que antes ni siquiera se sospechaba que existía entre nosotros... Indudablemente, aquellos libros hacían contraste con las novelas que habían formado el gusto refinado de la época, con las narraciones estetizantes de los decadentes, en los cuales hombres y mujeres, bien instalados en la vida, lloraban por penurias artificiales de amor o languidecían de tisis entre almohadones de plumas y muebles mullidos y acogedores. (Melfi 73-74)

Aquel proceso novedoso que confrontaba dos poéticas narrativas distintas sin duda que transformó los hábitos lectores finiseculares y fue transformando, también, la producción literaria. El mundo cambiaba, la cuestión social comenzaba a minar diversos campos. Pronto, con la Rerum Novarum (1891) de León XIII, surgirían las encíclicas sociales. Una tonalidad general de sensibilidad social alcanzaba los círculos intelectuales y, de alguna manera, orientaba el tenor de una estética que ya había corrido su medio siglo en Francia pero que en Chile comenzaba a estrenarse.

A fines de la década de 1880-90, un período donde ya se había comentado bastante en las revistas sobre el realismo y naturalismo europeos, aparece quizás el documento más relevante en esa línea, y que es el extenso ensayo de Pedro Balmaceda Toro titulado La novela social contemporánea, publicado junto a otros artículos del joven intelectual en 1889 bajo el título de Estudios i ensayos literarios. Entre otros aspectos, reflexiona sobre el realismo como una nueva estética.

Domina en el terreno literario una teoría, que desde tiempo atras viene luchando esforzadamente por conquistar el cetro de la belleza, por dominar las creaciones del arte; teoría revolucionaria, que, a la vez que es el resultado de una série de esfuerzos, significa el triunfo 
de la idea moderna; corriente de civilizacion que arrastra a su paso las estátuas del paganismo, las Vénus i los Apolos de mármol, las trajedias clásicas de Racine, i las lágrimas cinceladas de la escuela romántica ${ }^{1}$. (161)

Balmaceda Toro postula que el surgimiento de la escuela realista tiene raíz fundamentalmente en las disensiones con la escuela romántica (163) la cual, aun cuando presentaba hermosos ideales, tenía el defecto de no representar la realidad. Este proceso concreto se originó con la aparición de "Balzac, los Goncourt y Flaubert" (165). Balzac, con su Comedia humana,

ha planteado el estudio de los caracteres, de las pasiones, de las necesidades del individuo, para demostrar el modo como la vida se ve influenciada por el medio en que nace el hombre, el círculo en que se desarrolla su espíritu, la lucha constante del trabajo, i esos mil elementos desconocidos que contribuyen a formar el corazón, i que sin ellos, no podrían comprenderse las acciones ni los móviles que impulsan a la sociedad. (165-166)

Flaubert, con su Madame Bovary, "perfeccionó a Balzac" (167), pues

[n] unca hasta entonces se había escrito una obra que, como la de Flaubert, fuera mas profundamente sentida, mas real, de mas vigor, i en donde el análisis, la observación i la fisiología estuviesen más encubiertos por páginas de admirable estilo i de una emoción desconsoladora. (168)

Los hermanos Goncourt "contribuyeron en gran parte a la evolucion de la escuela realista" (169) de una forma muy especial, pues "tomaron del romanticismo el culto de la belleza, i del realismo esa verdad de colorido, que hizo de ellos, los escultores, por decirlo así, mas audaces de la pasión" (169-170). Daudet contribuye con su sensibilidad meridional delicada y sensible que le asigna colores vibrantes a la pintura realista. Y, después de otros, viene finalmente Zola, quien, leyendo las páginas de Balmaceda Toro, viene a representar una escuela que lleva la novela social al imperio de las leyes científicas, cuestión que lleva a la novela al ámbito de las premisas "hipotéticamente reales", abriéndola a la sospecha de superar el realismo por una vía que finalmente la lleve a alejarse de la realidad.

Dado ese panorama histórico y ese resumen de semblanzas literarias en donde aparecen los grandes nombres trabajados por Balmaceda Toro, queda por preguntarse qué entiende por la novela social y cuál es su relación con las necesidades que vive la sociedad de su tiempo. Para responder, es necesario citar que, para él,

[e]s a la novela de hoi, a la novela realista, a quien deberá la historia el conocimiento, el detalle revelador, la cifra fisiolójica, las

1 Se respeta la ortografía puntual y acentual original. 
pasiones encontradas, la lucha, la ajitacion, las conmociones de la multitud, de la sociedad, tan desconocidas hasta aquí, i que, sin embargo, son los grandes factores de la vida de un pueblo, de sus cambios políticos y sociales, de sus conquistas i de sus esfuerzos de civilización i de progreso. (205)

Es decir, asigna a la novela social un rol histórico, pues a ella exigirá el futuro evidencias, procesos y testimonios. Será este tipo de novela el que ofrecerá a las generaciones advenientes "la vida de muchos pueblos, con sus hombres i sus costumbres, i esta ajitacion activa del trabajo, de las evoluciones sociales que han transformado la historia, desterrando el dominio que sobre ella ejercían los predestinados de la fortuna i de la ambicion..." (207)

\section{La apropiación del relato social}

Reconocido el carácter de la primera recepción de la novela social europea, el próximo paso consiste en elaborar un bosquejo de los principales rasgos que tuvo la apropiación de las escuelas literarias naturalistas y realistas en el concierto de la producción narrativa de inicios del siglo XX. Siguiendo las reflexiones que Nelson Vergara ofrece en su artículo "Complejidad y cultura en la filosofía intercultural latinoamericana", quien retoma la idea propuesta por Fornet Betancourt en el sentido de que las "culturas son universos originarios" (Vergara, online), es posible plantear que, aun cuando el mundo cultural chileno, a comienzos del siglo XX, tenía apariencias de no ser más que un mosaico armado por la impostura cultural de variados productos y tendencias venidos desde afuera, sin duda también, dicho fenómeno constituye un esfuerzo para armar una cultura originaria, puesto que "originaria" no es, según Fornet Betancourt y según lo que de él dice Vergara, un "mundo aparte", existente desde antes, desde siempre, separado y autosuficiente. Por el contrario, "originaria es [...] una cultura que no excluye la interacción sino que más bien la supone como uno de los factores que la hacen posible históricamente, al confrontarse con otra" (Vergara, online). Dicha apertura a otras influencias a menudo no es inocente, pero señala, por su existencia, una cierta necesidad de lo otro.

Para el caso chileno, la apropiación literaria del realismo y del naturalismo en Chile, como se verá más adelante en algunos ejemplos, supone un encuentro entre varias tradiciones, lecturas y problemáticas. Cabe decir que la novela social chilena, como otras áreas de la creación literaria, se vio influenciada por el naciente modernismo. Los jóvenes escritores, algunos de ellos con una formación autodidacta, a menudo insertaban en un mismo cuerpo narrativo distintas escuelas no importando la posible incoherencia que ello pudiera suponer. Con el tiempo esta realidad ha tenido distintas evaluaciones. Indisciplina para algunos, color propio para otros. El caso es que, así, D'Halmar, Lillo, Edwards Bello, Orrego Luco, no son ni Zola ni Tolstoi; son, en cambio, quienes reciben el testigo de una preocupación, de una lectura, de una metodología literaria, de unos asuntos y temáticas universales, pero - al mismo tiempo - sujetos a 
variables influencias otras y haciendo habitar una práctica literaria en otro suelo. Su naturalismo y su realismo, evidentemente, han de tener también una marca distinta. Por este motivo, es injusto intentar reducir la obra de determinados autores a un corset formal según el cual nunca podrían dar "la talla" adecuada y resultarían simplemente inferiores a la obra de sus maestros.

De todos modos, hay algunos casos en que se dio una suerte de fijación de imagen propiciada por la recepción que sus obras tuvieron. Así, por ejemplo, con respecto a uno de los escritores que están en el origen de este proceso, Augusto D'Halmar, antes de publicar su novela Juana Lucero (1902), se hizo necesario que ella fuera anunciada por la prensa cultural del momento, la cual, amén de indicar las características de esta obra en presentación, de alguna manera situó al novel escritor en una línea determinada de producción asociándolo a los beneficios y a las limitaciones que dicha imagen produzca. De este modo, D'Halmar, durante mucho tiempo, y para los que incluso ahora no lo conocen lo suficiente, siguió siendo el "Zola hispanoamericano", por cuanto sería quien, en su primera novela, interpretó mejor los rasgos de la narrativa social que, llegando a Chile, desdibujó sus límites y se convirtió en una interesante mezcla de tolstoísmo realista y naturalismo zolaniano. No fueron suficientes las incursiones del autor chileno en el simbolismo francés ni tampoco bastaron veinte años de escritura exotista; siempre siguió siendo considerado un escritor naturalista. La imagen que la revista cultural transmitió de él lo fijó en un rol y pocos pudieron (o quisieron) hacerlo salir de él.

Estoy por creer que en muchas ocasiones su pintura realista lo convierte en un ser cruel. Zola, a la edad de Thomson (D'Halmar) era acaso más humano, o más bien dicho, tenía más piedad con los heridos, con los enfermos del pudridero humano. (Nadir, ILS 28, 5)

D'Halmar, en efecto, se convirtió en el exponente de una narrativa social que estuvo al inicio de su proceso creativo. Juana Lucero es el primer y casi único exponente de ello. En dicha novela, que comenzaba una serie de tres relatos titulada "Los vicios de Chile", se recoge la visión del arte comprometido postulado por Tolstoi y el método experimental de Zola (he aquí la integración). Una joven que, tras sucesivos abandonos, termina siendo arrojada por la sociedad al "pudridero humano" que es la prostitución, para después utilizarla en su beneficio. Una obra, sin duda, marcada por su carácter social, pero no menos que por las concepciones religiosas que atraviesan la novela, así como las creencias espiritistas y, por cierto, el final de tono simbolista que termina protegiendo a la joven Juana-Naná en el sueño de la locura. Esta es la originalidad de que se hablaba anteriormente; esto es su apropiación literaria.

Muchos han leído, era inevitable, la primera obra de Baldomero Lillo, Sub Terra (1904) a la luz de la novela Germinal, de Emile Zola, deduciendo su carácter naturalista. Sin embargo, pocos han visto en ella las influencias de Bret Hart, y sus cuentos mineros leídos por el padre de Lillo, que había estado en 
California, a los pequeños hermanos, en su casa de Lota. Y, tampoco reconocen las lecturas que Lillo hizo de la obra Recuerdos del pasado de Vicente Pérez Rosales. Evidentemente, la cuestión social y el determinismo marcan la naturaleza de los cuentos del narrador sureño, pero también ofrecen su atención a una práctica cuentística que tiene otros orígenes.

En el caso de la novela Casa grande (1908), de Luis Orrego Luco, se puede advertir una lectura de la problemática social vista desde su origen mismo, es decir, en la corrupción de la oligarquía chilena. Los desórdenes económicos y las injusticias sociales son producidos, sin duda, por una clase que especula con el dinero, que vive siempre en clima aspiracional y que se consume en los lujos exigidos por el "buen tono" a toda familia que quiera ocupar un lugar en la "aristocracia criolla". Ya D'Halmar lo decía, en sus Recuerdos olvidados, que, por entonces, era deber de las grandes familias tener una mansión en el centro de la ciudad, un coche para movilizarse, un fundo en el campo y un abono en el Teatro Municipal. Ese escenario social, armado de ciertos "deberes de clase" aparece muy bien reflejado en la obra de Orrego Luco, reforzado, además, por el determinismo genético que causa estragos en una familia que, habiendo tenido miembros tarados, está destinada por ley de naturaleza (Zola nuevamente) a tener hijos tarados, alegoría, por otra parte, de las taras de la clase alta que, por haber practicado por décadas una especia de endogamia de clase (social, económica y políticamente), ha terminado por generar esos hijos monstruosos que, de vez en cuando, ocultan las familias adineradas; hijos que, al mismo tiempo, son vergüenza para ellos y efecto de sus prácticas genealógicas.

Distinto es el "roto", presentado en la novela de ese nombre (1920) de Joaquín Edwards Bello, en quien se advierte la suerte de una supervivencia ante las adversidades de la vida gracias a una especie de selección natural que ha permitido que un ser debilitado moralmente sea, al contrario, fortalecido físicamente.

[...] para ser roto es menester criarse "peligrosamente" (como decía Nietzsche) y vencer el peligro. La fuerza física obtenida desde la infancia por una victoria en el "combate de la vida", he ahí la primera característica del roto, he ahí su cualidad fundamental de donde se derivan las demás. (Vaïse, 187)

El roto de Edwards es similar a la rapiña, personaje de un cuento homónimo de D'Halmar:

Larva de mujer: aquella muchachita enclenque, de ojos insolentemente provocativos, ofrecía diarios en la vereda del Club de septiembre, y en las altas horas, cuando los jugadores concluían su velada, lloviese ó platease la luna la acera, estábamos seguros de encontrarla, disputando siempre con el guardián del punto que la incomodaba con la amenaza de hacerla quitarse del umbral. [...] En el gremio de los suplementeros, la llamaban La Rapiña, por sus terribles uñas para pelearse con ellos ó para robar cualquier muestra 
de tiendas: ¡era una joyita aquella chica, tan lince, tan desenfadada, tan atrevida! Recién su iniciación en la vida del diarismo, sus colegas la burlaban, pero luego debieron convencerse que era digna camarada del más pintado de ellos. (ILS 39, 7).

El roto, la rapiña, varios personajes de Baldomero Lillo, son personajes de excepción, productos casi de la selección natural, experimentos literarios que dan cuenta del naturalismo determinista y sus relaciones con el darwinismo evolucionista. Algunos de ellos son capaces de sobreponerse ante las adversidades conservando un tono moral amargo pero probo; otros, en cambio, hijos de un naturalismo más severo, dan cuenta de que la estructura social en que viven, el mundo en que les cupo nacer, no ofrece para ellos sino la alternativa de la sobrevivencia que se gana sólo por una convenida y oportuna bajeza moral, que, por su justificación vivencial, ya ni siquiera merece el calificativo de moral o inmoral, pues para ello necesitaría contar con un requisito previo cual es la capacidad de elegir.

Detrás de estos ejemplos, hay una serie más amplia de novelas y cuentos que enriquecieron la producción cultural no sólo de inicios, sino de buena parte del siglo XX. Se recoge la cuestión social, se la acomoda al suelo nacional, se la transmite literariamente desde simples relatos casi costumbristas hasta novelas de alta rigurosidad naturalista. En todos los casos, es posible verificar la presencia de un influjo que tiene en Tolstoi y en Zola sus principales orígenes.

\section{Conclusiones: sociedad y proyecto narrativo de 1900}

La preocupación social resulta ser de tal importancia en la literatura que incluso ha sido posible ver en ella un eje estructurante para la formación de un panorama de las tendencias literarias de la época. Así, por ejemplo, George Smith, en su artículo "The Chilean Literary Scene: 1900" (1960), afirmaba:

We see, then, three definitive sub-trends in the Generation of 1900. A leaning of some writers toward the campo on the one hand is balanced by those who find their muse in the lowest districts of the large metrópolis. Both of these groups are inspired by the land, however. A third group refuses terrestrial or geographic bounds and sees within each individual a new unexplored, international territory offering a multi-faceted source of inspiration. (Smith 554)

Advierte Smith dos grandes tendencias: una localista y otra universalista. Dentro de la tendencia localista, están los dos escenarios fundamentales: el campo y la ciudad; de la ciudad menciona los bajos fondos.

Ahora, en un cuadro que recoja más detalladamente la influencia del realismo y el naturalismo en Chile debería haber algunos matices importantes. Así por ejemplo, que la narrativa rural tuvo también sus ámbitos de especialidad: Mariano Latorre y Federico Gana, el campo correspondiente a la zona central 
del país; Baldomero Lillo, las minas del sur, en Sub Terra y, también el campo agrícola en Sub Sole. Se sabe, además, que Baldomero Lillo quiso realizar una novela de las salitreras, proyecto que no pudo acabar y que habría completado su visión de la cuestión social en distintas realidades en donde el minero, el campesino, e incluso el hombre de mar, debían combatir contra las fuerzas de la naturaleza y los determinismos sociales que les impedían levantar cabeza.

Habría que agregar, además, que la novela urbana no sólo se entretuvo en los bajos fondos, como lo hizo en El roto, de Joaquín Edwards Bello. También lo hizo en los vicios de la alta sociedad, como en la novela ya comentada de Orrego Luco y, si se quiere, en esa conexión que hay entre clases sociales y que se muestra en Juana Lucero, aunque, bien sea dicho, los que conducen a la niña Juana a la abyección también representan distintas subclases (la clase política representada por un padre parlamentario que ignora a su hija, la clase funcionaria representada por el hombre que viola a la joven en la inmediaciones de la plaza Yungay, la clase aspiracional que aparece en los muchos personajes que sin pertenecer a la aristocracia quieren verse y mostrarse como tal). Estas novelas constituyen un mapeo de las situaciones más variadas de la sociedad chilena del '900, en las que se incluye la presencia de las casas de tolerancia, de las clínicas ginecológicas (para abortos y restauración de virgos), las simulaciones de poderío entre las clases aspiracionales o en bancarrota, el escándalo de la especulación financiera, la explotación laboral, el hambre, la miseria, el vagabundeo, y, entre otras realidades más, la presencia del huacho que, en versiones femeninas y masculinas, constituye una marca nacional, casi una señal del destino que acompaña a los pobres en una sociedad donde se es "huacho" por ausencia de padres, o se es "tarado" por repetición de los mismos, es decir, por la endogamia genética de un grupo de la sociedad que no reconoce a otros como válidos y termina por engendrar monstruos originados por su autosuficiencia de clase. "De huachos y tarados" sería el título y la síntesis de una sociedad que se refleja en la novela chilena como abandonada o como esperpéntica, y es, ciertamente, una temática en que ahonda lo mejor de la tradición novelesca posterior, como sería, vgr., la producción escritural de José Donoso.

Pues bien, en una y otra será posible reconocer influjos zolanianos, tolstoyanos y otros más. Vienen mezclados en una mélange que por un lado habla de determinismos (sociales, ambientales, genéticos), por otro de sensibilidad por las víctimas "del pudridero humano", por otro de cercanía al hombre de campo como lo haría Tolstoi al mujik o, por el contrario, como lo haría Zola a la "bestia humana". En todo caso, un proyecto que, en su conjunto, bien podría hacer de ésa nuestra propia "Comedia Humana".

Si Pedro Balmaceda Toro veía en la novela social un venero de información histórica de incalculable valor, entonces bien se puede decir que el conjunto de la narrativa social de las primeras décadas del siglo XX, la del otro centenario, con sus seguimientos y fidelidades particulares a los grandes realistas y naturalistas europeos, ofrece un cuadro de las verdades y falsedades, de los logros y 
limitaciones de la sociedad de entonces. Nosotros sabemos que dicha narrativa no ha prevalecido sólo por eso, pues hay un proyecto estético que la valida y la hace prevalecer. Sin embargo, no nos hace bien desconocer que había en sus creadores unos móviles sensibles y una necesidad casi histórica por, como decía Zola, "poner en marcha la verdad"; y la literatura, el cuento, la novela, se consideraban para ello instrumentos eficaces.

\section{Bibliografía}

Balmaceda Toro, Pedro. Estudios i ensayos literarios. Santiago: Imprenta Cervantes. 1889: 157-207.

Catalán, Gonzalo. "Antecedentes sobre la transformación del campo literario en Chile entre 1890 y 1920". En Brunner, José Joaquín y Catalán, Gonzalo: Cinco estudios sobre sociedad y cultura. Santiago de Chile: Facultad Latinoamericana de Ciencias Sociales, FLACSO. 1985: 70-175

D'Halmar, Augusto. Recuerdos olvidados. Santiago, Chile: Nascimento. 1975.

Melfi, Domingo. Estudios de la literatura chilena. Santiago: Nascimento, 1938.

Nadir. "Nuestros colaboradores. Augusto G. Thomson". En Instantáneas de luz i sombra

Smith, George. "The Chilean Literary Scene: 1900”. Hispania, 1960, number 4: 552-558.

Thomson, Augusto G. "La rapiña". En Instantáneas de luz i sombra. Santiago de Chile, 1901, 67: 1-2.

Thomson, Augusto G. "El gran encantador". En Instantáneas de luz i sombra. Santiago de Chile, 1900, 39:2-3.

Vergara, Nelson. "Complejidad y cultura en la filosofía intercultural latinoamericana". Osorno: Alpha, n²6. Universidad de los lagos, 2008. En http://www.scielo.cl/pdf/alpha/n26/art15.pdf. Revisado el 20 de abril de 2010. 